\title{
EL ANÁLISIS DE LA POBREZA \\ Y LA CAMPAÑA CONTRA LA MENDICIDAD \\ EN LA CIUDAD DE MÉXICO, 1929-1931
}

\author{
María Dolores Lorenzo \\ Universidad Nacional Autónoma de México
}

F n México, entre 1929 y 1930 se analizó la mendicidad porBeneficencia Pública aspiraban a resolverlo. Aunque durante el siglo xix la mendicidad fue relativamente tolerada, en la década de los años treinta del siglo xx la necesidad de acabar con la práctica de mendigar, que algunos pobres empleaban para subsistir, se presentó como un problema novedoso.

En las siguientes páginas mostraré cómo el análisis y el diagnóstico de la mendicidad, entreverados con las acciones de la Beneficencia Pública de recoger, clasificar y asistir a los indigentes, otorgaron un nuevo sentido a lo que se entendió por pobreza urbana desde el Estado. Expongo, pues, de qué manera los métodos aplicados de la sociología brindaron explicaciones remozadas respecto de los pobres y de las causas de su indigencia, y en qué sentido el análisis de la pobreza fue diferenciando la asistencia social para los considerados desvalidos, de la seguridad social, que debía otorgarse por derecho a los trabajadores.

Fecha de recepción: 25 de mayo de 2017

Fecha de aceptación: 25 de julio de 2017 
La historia de la política social en México ha privilegiado el estudio de los obreros y veteranos de la Revolución, así como el de los huérfanos, viudas, madres trabajadoras y sus hijos, porque fueron centrales en la reestructuración de los programas de protección social en la ciudad durante la posrevolución. Esta historia ha concedido atención significativa a los trabajadores sindicalizados y a los empleados, públicos y privados, quienes, con base en los contratos formales de trabajo, fueron integrados en el proyecto corporativo de seguridad social. Empero, estos grupos de la población no representaron al grueso de quienes quedaron al margen de los beneficios de la seguridad social, por lo cual nuestro propósito es aportar al estudio de los orígenes de una política social que pretendió asistir a los pobres desvalidos.

Este artículo centra su atención en las personas que idearon y gestionaron políticas sociales $y$, asimismo, reconoce a los indigentes que, por diversas razones - como la enfermedad y las discapacidades físicas o mentales - carecieron de medios de subsistencia y no contaron con redes familiares de apoyo que los proveyeran de techo, alimento, educación o salud. Para ello, exploro los ajustes pragmáticos que, entre 1930 y 1931, desde la Beneficencia Pública se llevaron a cabo para atender las necesidades de algunos grupos de pobres en la ciudad. Muestro que, cuando los indigentes desvalidos fueron asistidos, la Beneficencia los estigmatizó por sus condiciones de miseria. Con todo, los pobres que fueron atendidos en asilos, escuelas y hospitales públicos se convirtieron en depositarios de la asistencia social de cuyos beneficios, cabe señalar, otros indigentes quedaron al margen. ${ }^{1}$

En esta investigación, nos acercamos a la historia de quienes tuvieron la autoridad para definir qué era la pobreza urbana y cómo había de perfilarse al destinatario de la protección social

\footnotetext{
${ }^{1}$ No fue sino hasta el periodo presidencial de Lázaro Cárdenas cuando se dotó de un nuevo sentido al concepto de asistencia pública. Además, se modificó la estructura administrativa de la asistencia pública elevándola a Secretaría de Estado. Guadarrama, Entre la caridad, p. 109.
} 
en el marco de un trascendente y novedoso programa contra la mendicidad. El carácter prioritario de este proyecto de asistencia social fue avalado por la Presidencia de la República. ${ }^{2}$ En él participó activamente Moisés Sáenz, como director de la Beneficencia Pública del Distrito Federal. ${ }^{3}$ También el director del Departamento de Educación de la Beneficencia Pública, Ramón Beteta, colaboró en el estudio de la mendicidad y en el diseño de la política de protección a los desvalidos. ${ }^{4}$ Eyler $\mathrm{N}$.

2 AHSS, BP, DG, AS, leg. 3, exp. 8, 1930, (7 de agosto de 1930). Por disposición del presidente Emilio Portes Gil se inició el estudio de la mendicidad que se tradujo en la campaña contra la mendicidad impulsada por Pascual Ortiz Rubio. Por conducto de la Junta Directiva de la Beneficencia se notificó que el presidente solicitaba que todos los directores de las instituciones de asistencia colaboraran con este proyecto. En la práctica, los establecimientos de asistencia debían considerar a los mendigos como destinatarios de sus servicios.

3 Moisés Sáenz nació en Nuevo León en 1888. Se formó en el Seminario Presbiteriano de la Ciudad de México y como maestro normalista en Jalapa. Fue hermano del político Aarón Sáenz, hombre cercano al presidente Álvaro Obregón. Se doctoró en la Universidad de Columbia con una beca de la Universidad Nacional de México, la cual recibió después de oponerse al proyecto educativo de José Vasconcelos. Ocupó la Subsecretaría de Educación Pública (1924-1928); ahí, destacó como promotor de la escuela rural y del intercambio académico con estudiantes latinoamericanos. Sáenz fue nombrado por el presidente Emilio Portes Gil presidente de la Junta de Beneficencia Pública del Distrito Federal en febrero de 1930. En un complejo conflicto de facciones, renunció a este cargo por presión del presidente en turno, Pascual Ortiz Rubio, el 13 de junio de 1931. Del efímero periodo de Moisés Sáenz en la dirección de la Beneficencia existen pocas referencias en la historiografía, quizá porque fueron los años posteriores, durante el cardenismo, cuando la labor de Moisés Sáenz fue más destacada. Al respecto, es considerado por Jean Pierre Bastián el padre del indigenismo, porque consolidó instituciones y proyectos que impulsaron, desde el Estado, la "incorporación del indio". Bastian, Los disidentes, p. 153; Civera, La escuela como opción, p. 44. Otras acciones destacadas en la SEP: RiverA MIR, “La experiencia de los centroamericanos”, pp. 185-214.

${ }^{4}$ Ramón Beteta nació en la Ciudad de México en 1901; se graduó como abogado en la Escuela Nacional de Jurisprudencia; estudió en la Universidad de Texas en los años de 1920 a 1923. En 1934, obtuvo el grado de doctor en Ciencias Sociales en la Universidad Nacional. De su carrera como funcionario público destacamos que fungió como jefe del Departamento de Acción Educativa, 
Simpson, ${ }^{5}$ destacado sociólogo de la Universidad de Chicago, fue invitado por Sáenz y Beteta para trabajar con ellos, con lo cual se internacionalizó la mirada de los expertos en la formulación de esta política pública. ${ }^{6}$

A lo largo del texto nos referimos al estudio de la mendicidad elaborado por Beteta y Simpson porque aunque formalmente fue Beteta quien publicó los resultados de la investigación que patrocinó la Beneficencia en su libro La mendicidad en México, sin embargo, siempre reconoció que Eyler Simpson colaboró con él en este estudio. Con base en los documentos del archivo de Simpson, constatamos que el sociólogo estadounidense reportó, como parte de sus actividades del Institute of Current

Eficiencia y Catastros Sociales en 1930. En esta instancia, elaboró las estadísticas de las campañas contra la mendicidad. De la trayectoria académica de Beteta señalamos su interés por el derecho y los asuntos fiscales, así como su participación en la formación de la Escuela Nacional de Economía. De sus vínculos políticos resalta la estrecha colaboración con Moisés Sáenz en diferentes tareas de gobierno. Es de notar, sin embargo, que en sus biografías y en las referencias a su trayectoria apenas se menciona su activa participación en el diseño de programas de asistencia social de la posrevolución. Esta omisión se puede explicar por la destacada labor que llevó a cabo en la Secretaría de Hacienda en el periodo presidencial de Miguel Alemán. Llinás, Vida y obra, pp. 9-11. ${ }^{5}$ Eyler N. Simpson nació en San Antonio Texas en 1900. Por medio del programa de verano para extranjeros, Simpson se relacionó con algunos intelectuales políticos mexicanos vinculados a la Universidad Nacional de México. Eyler N. Simpson, como Beteta, egresó de la Universidad de Texas, aunque obtuvo el grado de doctor en Sociología en la Universidad de Chicago. Entre 1927 y 1935 vivió en México; durante su estancia fungió como representante del Institute of Current Public Affairs y colaboró en diversos proyectos relacionados con los problemas sociales del país: cuestión agraria, pobreza, educación de los maestros rurales y de los indígenas; también estudió en la Universidad Nacional. En 1937, regresó a Estados Unidos como profesor de la Universidad de Princeton. Murió en 1938. Delpar, Looking south, p. 89; Wheat, "Personal encounters".

${ }^{6}$ Respecto de los intercambios socioculturales entre México y Estados Unidos en el contexto de la crisis de 1929, véase Delpar, Looking South, pp. 73-89; Riguzzi y De los Ríos, Las relaciones, pp. 270-276.

7 Beteta, La mendicidad en México. 
World Affairs, del cual era representante en México, la elaboración de las secciones I y II de la investigación sobre la mendicidad. ${ }^{8}$ En cuanto al trabajo práctico, Simpson formó a los inspectores de la Beneficencia en los métodos aplicados de la sociología y del trabajo social que se desarrollaron en la Universidad de Chicago en esos años. Beteta, por su parte, se encargó de la recopilación de datos estadísticos y de encaminar el destino asistencial de los indigentes durante la campaña contra la mendicidad. Esta documentación, dispersa en distintos fondos del Archivo Histórico de la Secretaría de Salud y en la Universidad de Texas, junto con las noticias publicadas en los periódicos de la época, sustentan la investigación.

Los políticos y los científicos sociales cercanos al poder actuaron en coordinación con otros empleados de la Beneficencia y del gobierno del Distrito Federal que intervinieron en la ejecución de esta política pública. Las experiencias de gestión y las prácticas cotidianas de los involucrados en el tratamiento de la mendicidad contribuyeron a la construcción de una nueva forma de entender y gobernar la pobreza desde el Estado; por ello, exploramos el quehacer de los trabajadores sociales, que se formaron como inspectores de la Beneficencia y que clasificaron a los mendigos. Asimismo, nos referimos a los policías, que recogieron a los pobres en las calles. La prensa, que le dio seguimiento a la campaña contra la mendicidad, también ocupó un lugar entre los actores que redefinieron una nueva forma de entender la pobreza urbana en la Ciudad de México.

Resta por señalar que este artículo se organizó en tres partes: en la primera, expongo las características y los resultados del estudio de la mendicidad; en la segunda, presento qué se entendió por pobre y pobreza en el ámbito de la Beneficencia y cuáles fueron las recomendaciones para acabar con la mendicidad en

\footnotetext{
${ }_{8}^{8}$ Biblioteca de la Universidad de Texas, Mexican Manuscript Collection, Eyler Simpson, "Memorandum in Re, The Mexican Post, 1927-1931".
} 
la ciudad, y, por último, en la tercera parte, muestro los resultados concretos de la campaña contra la mendicidad en México durante 1930-1931.

\section{El contexto}

El punto de partida para esta investigación consideró dos procesos enlazados que le dieron sentido a las preguntas ¿qué fue ser pobre? y ¿cómo paliar la indigencia en la ciudad? En primer lugar, podemos advertir que una motivación que precipitó la articulación de políticas sociales fue la respuesta del gobierno ante las condiciones de miseria que provocó la estrepitosa urbanización y los efectos de la industrialización en la ciudad de México. ${ }^{9}$ Además, las políticas sociales emprendidas durante los gobiernos de Emilio Portes Gil (1928-1930) y Pascual Ortiz Rubio (1930-1932) coincidieron con el interés mundial de brindar respuestas efectivas para reducir el desempleo, cubrir la carencia de vivienda y erradicar la mendicidad, que proliferaron en el mundo como consecuencia del colapso financiero de 1929. En México, entre 1929 y 1931, la economía resintió la disminución de la demanda externa, la reducción de la oferta monetaria y la contracción del gasto público. Las utilidades en la industria se redujeron y miles de trabajadores perdieron sus empleos. Más de 310000 mexicanos fueron repatriados de Estados Unidos entre 1929 y 1933: creció el número de desempleados y se perdió un importante ingreso de divisas. ${ }^{10}$

En segundo lugar, sabemos que, desde los años veinte, los gobiernos de la posrevolución favorecieron el acercamiento con los antropólogos, médicos, higienistas, abogados y maestros.

\footnotetext{
9 La población total del Distrito Federal pasó de 720753 habitantes en 1910 a 1029068 habitantes en 1930. En dos décadas la población aumentó 308315 habitantes. Censo General de la República Mexicana, 1910 y Quinto Censo de Población, 1930.

10 CÁrdenas, "La economía mexicana”, p. 506.
} 
Desde sus disciplinas, estos profesionistas proyectaron iniciativas que se transformaron en políticas sociales, las cuales procuraron extender la educación primaria y la alfabetización, además de ampliar la cobertura en materia de salud e higiene pública. Atentos a la precaria situación de los indígenas, también articularon políticas indigenistas y gestaron proyectos de "profilaxis social" que introdujeron la cuestión de la "raza" en el campo de la educación, la salud y la criminología. ${ }^{11}$

Los recursos que la Beneficencia Pública destinó para asistir a los pobres fueron muy limitados..$^{12}$ Entre 1929 y 1931, se entendió que solo se auxiliaría a los extremadamente pobres en una gestión atenida al escueto presupuesto de la Beneficencia del Distrito Federal. Dadas estas restricciones, la Beneficencia coordinó algunas acciones sociales con otras instancias del gobierno, como fue el recogimiento de mendigos que asumió el Distrito Federal. No obstante los límites presupuestales impuestos a la campaña de la mendicidad y a otros programas de la

${ }^{11}$ Urías, "Eugenesia y aborto", p. 308; Agostoni, Médicos, campañas, pp. 136-137. Respecto del discurso posrevolucionario en materia de acciones de salud y educación públicas, véase ArÉCHIGA, “Educación”. En cuanto al programa de "ingeniería social" en la posrevolución que concibió la construcción de una nueva sociedad a partir de transformaciones físicas y mentales y con la intervención de las ciencias sociales, además de médicos e higienistas, véase URÍAS, "Locura”. Entre 1920 y 1940, la colaboración entre científicos sociales, mexicanos y estadounidenses fue significativa en la construcción de problemas sociales, además del desarrollo de las ciencias sociales en México. Para la década de 1920-1930 véase Tenorio, "Stereophonic"; para la década de los años treinta, Palacios, "The Social”. Por ejemplo, para los estudios migratorios véase Durand, "Un punto de partida", pp. 51-64.

${ }^{12}$ El presupuesto mensual aproximado que destinó la Beneficencia a la campaña contra la mendicidad fue de 6000 pesos y no se incrementó en los años que estudiamos (1929-1931). AHSS, BP, D, AS, leg. 13, exp. 17, ff. 1-6 (1930). En la iniciativa de presupuestos federales de 1929 se blasonó un aumento del gasto público en el ramo de la Beneficencia; sin embargo, acotaron que el gobierno consideró " prudente limitar el desarrollo de los programas parciales de las dependencias" para no recurrir al aumento de impuestos o a incrementar la deuda pública. Riguzzi, Las exposiciones, p. 1404. 
Beneficencia, el presidente de la República rechazó la propuesta de colaboración de la Beneficencia Privada en este proyecto social del Estado. Es así que, a pesar de la renovación que supuso la introducción de métodos de las ciencias sociales en el análisis de la pobreza, las soluciones al problema debieron ajustarse al servicio que tradicionalmente se brindaba a los pobres en escuelas, asilos y hospitales públicos dependientes de la Beneficencia en el Distrito Federal.

\section{EL ESTUDIO DE BETETA Y SIMPSON: HACIA UNA NUEVA PERCEPCIÓN DE LA POBREZA}

En 1930, Moisés Sáenz, director de la Beneficencia Pública del Distrito Federal, impulsó uno de los primeros estudios que los gobiernos posrevolucionarios patrocinaron para abatir la mendicidad en la ciudad de México. Ramón Beteta dirigió la investigación, que debía servir de guía a las instituciones, públicas y privadas, interesadas en la "desaparición" de la mendicidad en la capital; para colaborar en esta investigación, Moisés Sáenz invitó al profesor de sociología de la Universidad de Chicago, Eyler N. Simpson.

La colaboración entre Beteta y Simpson fue estrecha. Aparte de las afinidades ideológicas al formular políticas públicas para atender algunas demandas sociales, Eyler Simpson y Ramón Beteta habían coincidido, como profesor y estudiante, respectivamente, en la Universidad de Texas entre 1920 y 1923. Además del estudio de la mendicidad, Beteta y Simpson trabajaron juntos en otra investigación que trató los problemas agrarios; la autoría del libro la asumió Simpson, aunque el prólogo lo elaboró Beteta. ${ }^{13}$

${ }^{13}$ Eyler N. Simpson, The Ejido. Mexicos's Way Out, Chapel Hill, University of North Carolina, 1937. En 1952 esta obra se tradujo con el título El ejido. Única salida para México. 
La autoridad ganada en el análisis social por los sociólogos de la Universidad de Chicago se forjó en los años de la primera posguerra, cuando el Departamento de Sociología de esa universidad se colocó a la vanguardia de la investigación de diversos problemas considerados entonces "patologías sociales".$^{14} \mathrm{En}$ el Departamento de Sociología de la Universidad de Chicago se desarrollaron métodos estadísticos y de análisis para el estudio de los homeless y de los afroamericanos que habitaban en los barrios marginales de la ciudad; además, se estudiaron los patrones de asentamiento de los migrantes mexicanos en Estados Unidos y de los habitantes ubicados en los cinturones de miseria en las ciudades estadounidenses, entre otros temas. ${ }^{15}$ Así, la invitación de la Beneficencia a Simpson tuvo la finalidad de introducir a los inspectores de la Beneficencia Pública en la metodología de las ciencias sociales que se desarrollaban en Chicago, pero aplicadas al estudio de los indigentes en México.

El intercambio entre académicos en materia de asistencia social no fue exclusivo de la relación entre México y Estados Unidos, ni tampoco se inició en la posrevolución. ${ }^{16}$ Ya desde finales del siglo XIX, la preocupación por explicar los efectos de las crisis sociales, guerras, migraciones masivas, etc., sobre los individuos y la sociedad, fomentó el intercambio de información entre investigadores de la Universidad de Chicago y altos

\footnotetext{
${ }_{14}$ Аввотт, Department. Respecto del conocimiento de la pobreza en este periodo véase O'Connor, Poverty Knowledge, pos. 1226.

${ }^{15}$ García Dauder, “La historia olvidada”, pp. 11-41; Sanguino y Tenorio, “Orígenes”, pp. 257-314; Howard, Homeless, pp. 150-151.

${ }_{16}$ Respecto de los intercambios de saberes sobre la pobreza y sus discursos véase May, "Poverty in Transnational"; O’Connor, Poverty Knowledge. Considero que la historia de la asistencia y la pobreza en México no había puesto suficiente atención en estos intercambios, tal como se ha enfatizado para otros campos de estudios como la historia social de la medicina, la antropología, la arqueología y el uso de métodos de las ciencias sociales como la estadística.
} 
funcionarios de las instancias asistenciales públicas mexicanas. ${ }^{17}$ Sin embargo, a diferencia del propósito que tuvieron a finales del siglo XIX de estudiar las instituciones de la asistencia para evaluar su eficacia, durante la posrevolución, la colaboración entre las autoridades de la Beneficencia y los científicos sociales tuvo por objeto brindar una versión calificada respecto de un problema social y guiar el diseño de las políticas antes de su ejecución, con la convicción de que los nuevos procedimientos científicos erradicarían las manifestaciones de la pobreza en la ciudad. ${ }^{18}$

Así, se pasó de recopilar información para evaluar hospicios, escuelas y hospitales como espacios de ayuda para el necesitado, a la investigación y el análisis de los problemas estructurales de la sociedad, que debían resolverse aplicando procedimientos calificados por los estudiosos y en combinación con los funcionarios públicos, que debían traducirlos en políticas públicas.

De la colaboración con los científicos sociales, reconocemos que se introdujeron al lenguaje de la investigación social de la pobreza y de la asistencia social, términos como "desorganización social", "desadaptados al medio social” o "desmoralización del individuo", cuyos significados fueron definiendo las explicaciones y causas de la indigencia en México. Estos conceptos contribuyeron con una reelaboración del sentido de la pobreza, la cual debía estudiarse a partir del análisis de los componentes culturales (ideológicos), las condiciones económicas y los comportamientos psicológicos relacionados con el medio social, lo anterior con el propósito de planificar políticas sociales que

17 Steelman, "Charities". Además de la tesis doctoral que Albert Judson Steelman, miembro del Departamento de Sociología Eclesiástica de la Universidad de Chicago, defendió en 1907, en México se publicaron otros libros que analizaron las instituciones de la Beneficencia en la ciudad como una forma para atender la indigencia de la población. Juan Abadiano, Establecimientos de beneficencia. Apuntes sobre su origen y relación de los actos de su junta directiva (1878); Juan de Dios Peza, La beneficencia en México, (1881), en LORENZO, Obras.

18 BeteTA, La mendicidad, p. 127. 
anhelaban acabar con la mendicidad y renovar el diseño y la acción social del gobierno sobre los pobres.

En la década de 1930 la investigación en la escuela de sociólogos de Chicago reconsideró la importancia de estudiar los factores económicos como determinantes en el análisis social y, de manera articulada, aunque no predominante, emplearon para el análisis el eje cultural que había predominado en la década de 1920 entre los antropólogos que estudiaron los problemas de la sociedad. ${ }^{19}$ Advertimos que, para el caso de México, la participación de Beteta y su perspectiva económica seguramente fue significativa en el enfoque del estudio cuantitativo de la mendicidad.

En este tránsito del quehacer de los estudiosos de los problemas sociales, la teoría fue tan importante como dar a conocer la innovación de los métodos de la sociología y del trabajo social. ${ }^{20}$ Para introducir a los inspectores de la Beneficencia en algunas metodologías como la observación empírica y algunas técnicas de entrevista, Ramón Beteta y Eyler Simpson organizaron una serie de conferencias. Simpson expuso que privilegiaría la enseñanza del "estudio de diagnóstico", cuya propuesta se sustentó en la formación de los métodos de recopilación empírica de "evidencias" relacionadas con los trastornos humanos y el medio social "afectado". ${ }^{21}$

Los primeros trabajadores sociales que formó la Beneficencia aprendieron la disciplina en el quehacer cotidiano de las labores de clasificación y del análisis de casos de los indigentes en el ámbito de las campañas contra la mendicidad. Paulatinamente,

19 O'Connor, Poverty Knowledge, pos. 1247.

20 Beteta, La mendicidad, p. 12.

21 "Los problemas sociales en México. Una serie de conferencias dada en el Departamento de Acción Educativa y Catastro Social de la Beneficencia Pública del Distrito Federal. 1ํㅡ de abril a $1^{\circ}$ de junio de 1930”, Benson Latin American Collection, University of Texas Libraries, The University of Texas at Austin. 
se concibió a las trabajadoras sociales como actores centrales en la reforma del tratamiento de la indigencia y como un grupo de empleados públicos que transformarían la administración y el gobierno de la pobreza urbana. ${ }^{22}$

El estudio de la mendicidad procuró apegarse al método de análisis social y, en unos cuantos días, los inspectores de la Beneficencia alistaron una especie de recuento de mendigos. Eyler N. Simpson consideró que la información estadística que había sobre la mendicidad en México era imprecisa e insuficiente para elaborar un diagnóstico de esta patología social. Por ello, se optó por cuantificar a los mendigos que se veían en las calles céntricas de la ciudad. Los primeros resultados del recuento elaborado por la Beneficencia cuestionaron las cifras de otras cuantificaciones de mendigos: frente a los 96 pordioseros registrados en el Censo de la República de 1910, y en contraste con los 5000 que registró la Inspección General de Policía, el estudio de Eyler Simpson, de modo aproximado, calculó que había 1000 mendigos en la capital. ${ }^{23}$

Para cotejar los datos que los inspectores de la Beneficencia obtuvieron de la observación de los mendigos, Beteta y Simpson no consideraron el recuento que, en 1879, el secretario del Asilo Particular de Mendigos, Felipe Ibáñez, había realizado en la ciudad de México y que, también con el método de observación directa, había cuantificado 1000 mendigos en la capital. ${ }^{24}$

22 SANDERs, Gender and Welfare, p. 125.

23 Beteta, La mendicidad, p. 11.

${ }^{24}$ Felipe Ibáñez fue secretario y administrador del Asilo Particular de Mendigos y el encargado de recopilar y publicar esta información. El indicio para afirmar que Simpson o Beteta conocieron los resultados del recuento de mendigos de 1879 es que ellos utilizaron, en la justificación histórica del proyecto, el trabajo de Juan de Dios Peza, quien apuntó la existencia del censo de Ibáñez. Además, en la Reseña Histórica del Asilo Particular de Mendigos, la cual también utilizaron para los antecedentes históricos, se destacó la tarea de recopilación estadística de la institución encargada de la mendicidad en la ciudad de México. Lorenzo, Obras. Véase Juan de Dios Peza, "La beneficencia 
Los estudiosos de la mendicidad en los años treinta eludieron la información cuantitativa que se publicó en 1880, quizá como un artilugio para aquilatar, con los "nuevos datos", la legitimidad de lo que se presentó como un nuevo saber respecto de la pobreza urbana. Es cierto que, a finales del siglo xix, Felipe Ibáñez mencionó el carácter improvisado de sus procedimientos para contar mendigos; en todo caso, podemos señalar que la presunta rigurosidad del método científico fue significativa para los investigadores de los años treinta que, en su investigación, acomodaron los datos estadísticos que consideraron más pertinentes.

Mil mendigos era una cifra poco significativa en relación con la población total de la ciudad. ${ }^{25}$ Empero, por su visibilidad en la vía pública, por la inevitable manera de hacer notar la miseria en la urbe y porque la mendicidad se percibió como una actividad que transgredía el orden, se identificó con comportamientos patológicos y nocivos para el sistema social, por lo cual se perfiló la propuesta de "extirpar" de las calles a los limosneros.

El diagnóstico científico sobrecargó con una pretensión de objetividad la taxonomía de un subgrupo de pobres, definidos por algunos supuestos sobre la indigencia. Así, los inspectores de la Beneficencia también clasificaron a quienes percibían como mendigos, por sexo, lugar de origen (rural y urbano) y condiciones físicas. ${ }^{26}$ No sabemos cómo se llegó a esos datos, pero es de

en México”, p. 177, y "Reseña histórico descriptiva del Asilo Particular para Mendigos", p. 332. Lorenzo, "Los mendigos", pp. 341-365.

${ }^{25}$ De acuerdo con el censo de 1930 se registraron 1029068 habitantes en el Distrito Federal. Mil mendigos en las calles representaban $0.1 \%$ de la población del Distrito Federal. Dirección Estadística Nacional, Quinto Censo de Población 1930. Tabulados básicos, "Poblaciones de las capitales de entidad". Recuperado el 17 de mayo de 2016 en http://www3.inegi.org.mx/sistemas/ tabuladosbasicos/default.aspx?c=16767\&s=est.

${ }^{26}$ El espacio escogido para llevar a cabo el conteo de pordioseros fue el distrito comercial de la ciudad de México. El trabajo de observación y cuantificación de los mendigos comenzó la mañana del martes 22 de mayo de 1930, pero a causa de la lluvia, los mendigos se dispersaron y los inspectores de la Beneficencia 
suponer que la diferenciación de los mendigos por su "origen" se hizo a partir de una valoración subjetiva. Tal vez, los inspectores apelaron a los imaginarios sociales y criterios relacionados con la "raza", así como representaciones y caracterizaciones de los trabajadores manuales y de los trabajadores agrícolas para definir a los sujetos de la mendicidad.

El reconocimiento visual de los pobres según la edad aparente mostró que el grueso de la población de los mendigos se concentraba entre los 20 y los 50 años de edad (véase la gráfica 1). Respecto de la condición de salud, 62\% de los mendigos contados parecían enfermos o tenían alguna limitación física que los incapacitaba para el trabajo. Del universo total de mendigos registrados, destacó que 38\% de esa población a simple vista parecía “sana” y apta para el trabajo de acuerdo con el criterio de los inspectores de la Beneficencia (véase la gráfica 2).

\section{Gráfica 1}

RESULTADO DE LA OBSERVACIÓN DE MENDIGOS SEGÚN GRUPO

DE EDAD, 22 Y 25 DE MAYO DE 1930

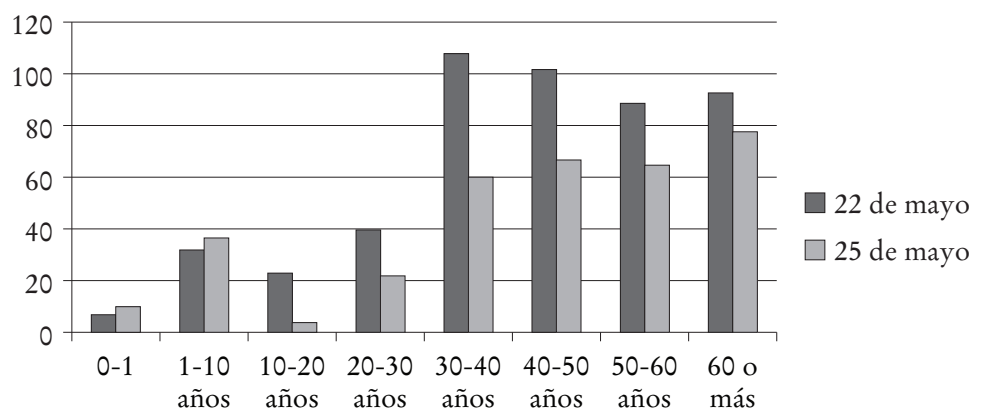

Fuente: Beteta, La mendicidad, pp. 13-14. De los 837 mendigos que conformaron el universo de la muestra del recuento, las mujeres representaron menos de $45 \%$ de los mendigos, y los hombres $55 \%$ del total del grupo de pordioseros.

tuvieron que revalidar el conteo de mendigos el domingo 25 mayo. 


\section{Gráfica 2}

RESULTADO DE LA OBSERVACIÓN DE MENDIGOS SEGÚN

SU CONDICIÓN FÍSICA APARENTE, MAYO DE 1930

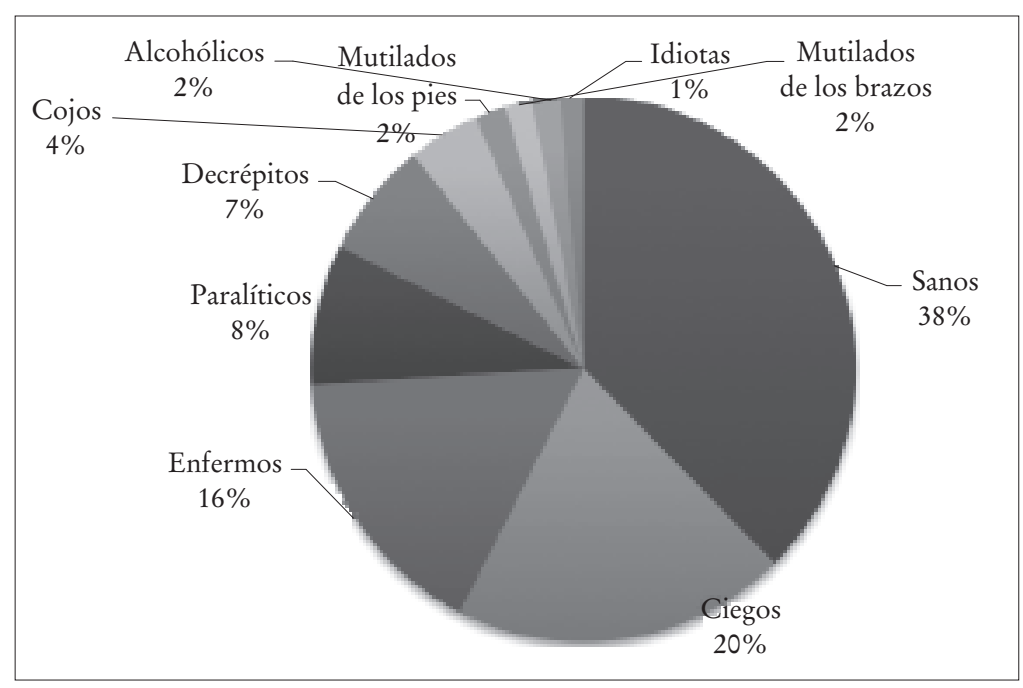

Fuente: Beteta, La mendicidad, pp. 13-14.

El recuento mostró la indigencia de una población enferma, y también reconoció la debilidad física de una población mutilada, ciega, paralítica y doliente, que encontró una forma de ganarse la vida en la mendicidad. Al respecto, destacamos la persistencia de las instituciones de asistencia en México que, desde finales del siglo xIx, fueron perfilando la vulnerabilidad de la población mendicante con la cuantificación y clasificación de estas personas según sus enfermedades. Cabe señalar también que, en 1930, como una población diferenciada, el Quinto Censo de Población registró a la "población con defectos físicos y mentales" con criterios semejantes a los del recuento de la Beneficencia en 1930 y de la relación cuantitativa de mendigos de finales del 
siglo XIX. ${ }^{27}$ Tomado en conjunto el interés por contar y clasificar a este subgrupo de la población, advertimos que, a partir de los criterios que definieron la enfermedad y los "defectos" de las personas, se fue reconociendo la condición de riesgo de una población considerada desvalida, sobre la cual era previsible la intervención social.

\section{Ciudad y pobreza}

De acuerdo con el estudio de Beteta y Simpson, las patologías sociales estaban directamente relacionadas con el medio social en el que se desarrollaban los individuos. A partir de esta lógica, fue indispensable reconocer el origen, urbano o rural, de los mendigos, pues explicaba la relación entre la mendicidad y los procesos migratorios del campo a la ciudad. Con el supuesto de que la gente que llegaba del campo a la ciudad tenía mayores dificultades para adaptarse al medio urbano, argüían que "con más frecuencia" los migrantes se encontraban embrollados en juicios criminales, en hospitales, en asilos y, en general, en todos los lugares "adonde van a parar los que tienen dificultades serias por inexperiencia”. ${ }^{28}$

Para corroborar la hipótesis del migrante y su tendencia al comportamiento "desadaptado", Beteta y Simpson reconocieron que había ciertos fenómenos "patológicos" característicos de los habitantes de las grandes ciudades que, si bien afectaban a la población urbana, quienes llegaban de poblaciones pequeñas a la capital se veían en el riesgo constante de ser "contagiados". Beteta y Simpson expusieron que en la ciudad de México el problema de la desorganización era más serio que en otras ciudades

${ }^{27}$ El Quinto Censo de Población en 1930 registró en la ciudad de México 7942 personas con "defectos físicos y mentales": ciegos, cojos, idiotas, jorobados, locos, mancos, mudos, sordos, sordomudos y tullidos fueron las categorías empleadas para este registro.

28 BeteTA, La mendicidad, p. 84. 
debido al rápido crecimiento demográfico, lo cual se acrecentaba como resultado de los inmigrantes que llegaban a la ciudad desde los pequeños pueblos que rodeaban la capital.

Los datos indicaron que aproximadamente la mitad de los mendigos tenían "aspecto rural" y la otra parte "parecía" de "origen citadino". Con esta información, el recuento corroboró que el abandono de algunos individuos del campo y su respectiva movilidad hacia la ciudad suscitaban una inserción perjudicial en la urbe, pues se incrementaba el nivel de desorganización. No se trató únicamente de la falta de capacidad adaptativa de los que llegaban desde las afueras de la ciudad, sino de la influencia negativa que la vida urbana imponía sobre la población que habitaba las ciudades en expansión.

El problema residió, según Beteta y Simpson, en que los grupos que necesitaban "cuidado o vigilancia" no hallaban formas de control adecuado en la ciudad porque éste era "flojo y transigente" $y$, en contraste con el "cuidado personal" que se ejercía sobre los indigentes en los pueblos pequeños, la ciudad carecía de esta contención. En este sentido, la ciudad de México, en plena expansión urbana y demográfica, de manera creciente exhibía "el fenómeno patológico de la desorganización". Como un riesgo y dada la "desadaptación" a su medio de origen, los migrantes eran vulnerables al "contagio" y "reproducción" de diversas patologías sociales, como el alcoholismo. Desde finales del siglo XIX y sobre todo después de la Revolución, la criminología en México coincidía también con esta perspectiva del desorden y la falta de contención en la capital. ${ }^{29}$

En la ciudad, el incremento en los índices de divorcio, suicidio y crimen se concibieron como manifestaciones de la desorganización, que se reproducían con facilidad y proporcionalmente

29 Beteta, La mendicidad, pp. 84-85. Piccato, Ciudad de sospechosos, p. 92. En la publicación de Beteta, la Revolución no aparece como un factor determinante del incremento de la criminalidad en la ciudad. 
a ritmos acelerados respecto de lo que sucedía en poblaciones pequeñas. El estudio apuntó que la tasa de suicidios había crecido entre 1917 y 1927 y que se mantenía en un rango de 27.4 suicidios por año; sin datos concretos, señalaron que el divorcio también crecía en la ciudad desde 1910 como causa de la desintegración familiar. El crimen era el dato más certero para mostrar el creciente fenómeno de la desorganización: en 1922 se habían registrado 27689 crímenes y en 1929 la cifra ascendía a $31917 .{ }^{30}$

El interés por registrar el origen rural de los pobres en el recuento de mendigos reflejó el propósito latente del gobierno de Ortiz Rubio por impulsar y reactivar las actividades agrícolas para devolver al campo algunos de sus trabajadores desplazados hacia la ciudad en los años de la Revolución. El campo se presentaba como la alternativa más viable para el desarrollo del país. ${ }^{31}$ Lo anterior, en coincidencia con la interpretación de los datos de población, producción industrial y agrícola que la Dirección Nacional de Estadística emitió entre 1929 y 1930, para mostrar que la reconstrucción del país se lograría con el estímulo de la producción del campo mexicano. ${ }^{32}$

Con el afán de impulsar políticas para el desarrollo del campo, Beteta y Simpson elaboraron, paralelamente al estudio de la mendicidad, un diagnóstico sobre la cuestión agraria que se publicó en The Ejido. Mexicos's Way Out. En el libro se expusieron datos de producción agrícola en México que alentaban la idea de corregir el desempleo en las ciudades, además, de frenar la migración del campo a la ciudad, impulsando los

\footnotetext{
30 BeteTA, La mendicidad, p. 85.

31 La antropología y la sociología dedicadas al estudio de los problemas sociales y étnicos centraron su atención en estudios instrumentales de comunidades indígenas, en relación con los problemas de la ciudad. Palacios, "The Social Science”, p. 62. No obstante, como señala Agostoni, "Médicos rurales", p. 140, la preponderancia del mundo urbano para entender los problemas de salud se explica, en parte, por una práctica desigual de la profesión médica, que privilegió su desarrollo en las ciudades.

32 Ervin, “The 1930 Agrarian Census”, pp. 549, 556.
} 
programas de fomento al sector agrícola que habían iniciado en la década de $1920 .{ }^{33}$

No obstante, la desigualdad en las condiciones de vida entre el campo y la ciudad inhibió la concreción de este anhelo, pues si bien, como apunta Alan Knight, el crecimiento de la producción en el campo mexicano pudo absorber el desempleo que suscitó la reducción de la economía de exportación industrial y urbana, ${ }^{34}$ los salarios de los campesinos eran reducidos, y las condiciones de vida en el campo se contrajeron a partir de 1929.35

Los salarios de los trabajadores en las ciudades tampoco se consideraron suficientes para sostener un nivel mínimo de subsistencia, lo cual condujo a la afirmación de que la pobreza era la causa principal de la mendicidad y que pedir limosna era, según Beteta y Simpson, "la segunda posibilidad" que algunos pobres tenían antes de morirse de hambre. ${ }^{36} \mathrm{Si}$ bien no se justificó la práctica de la mendicidad, el estudio mostró cierta conmiseración, que explicó la necesidad de los pobres de limosnear como uno de los últimos recursos extremos para la subsistencia, pero instó a atender el problema de la mendicidad y solucionarlo, reconociendo el origen multicausal de la pobreza urbana.

En vista de este análisis, los estudiosos de la pobreza expusieron a grandes rasgos que el estrepitoso crecimiento de la población en la urbe, el abandono del campo y la migración a la ciudad, las enfermedades de los desvalidos y la incapacidad para trabajar afectaban la vida de los habitantes más pobres.

\footnotetext{
33 La inversión social del gobierno se dirigió también al campo mexicano. La protección social y la procuración del bienestar de los campesinos se tradujo en campañas intensivas de salud, destinadas a erradicar algunas enfermedades de la población rural en la lógica de la expansión de la medicina social. AgOsTONI, “Médicos rurales", p. 136.

34 Knight, “Carácter y repercusiones”, pp. 282-283. Véase en ese texto la nota 38 con la información de la producción de maíz en México que elaboró Eyler N. Simpson en The Ejido.

${ }_{35}$ Montalvo Ortega, Historia de la cuestión agraria, p. 15.

36 BeteTA, La mendicidad, p. 33.
} 
Así, en medio de una crisis económica, sentaron las pautas para replantear la forma de conocer la pobreza mendicante y matizar su tratamiento desde la Beneficencia Pública.

INTEGRADOS Y REZAGADOS: ¿QUIÉNES FUERON LOS POBRES?

La pobreza nunca es un valor absoluto, sino que se especifica en relación con dimensiones diversas que no pueden ser designadas a priori. Empero, una manera de entender cómo definen la pobreza las sociedades es por medio del estudio de las categorías sociales y del diseño de las políticas que construyen los atributos de los pobres. De ahí mi interés en explorar la tipología de pobres que perfiló el estudio de la mendicidad entre 1929 y 1930.

La construcción de las tipologías de la mendicidad plasmó los supuestos que el grupo de investigación dirigido por Ramón Beteta concibió para explicar las causas de la mendicidad. Las variables sobre las que trabajaron para denotar lo que llamaron "enfermedad social" fueron: el ciclo de vida, la incapacidad física y mental para laborar, algunas cuestiones ideológicas (influencia de la religión) y el desempleo, además de las causas relacionadas con la moral y la degradación, tales como el alcoholismo y la criminalidad. La investigación consideró algunas explicaciones relacionadas con la migración, la guerra y la carencia de redes, que se entreveraron con las causas tradicionales del riesgo social y la vulnerabilidad de este grupo de indigentes, por sus incapacidades físicas o mentales para laborar, o bien por su fragilidad en ciertas etapas de la vida, según el grupo etario: niños o ancianos. ${ }^{37}$

Los casos ideales que identificaron la mendicidad en el estudio de Beteta y Simpson fueron la representación del niño

${ }^{37}$ A diferencia de la asistencia dirigida a los niños, aspecto central para la Beneficencia en el siglo xIx, los ancianos recibieron de manera acotada el socorro público y privado y sólo hacia finales del siglo XIX algunos asilos privados focalizaron su objetivo en los ancianos. VIVALdo, "Viejos y ancianos". 
mendigo, el mendigo profesional, el mendigo por falta de trabajo, el mendigo físicamente incapacitado ("cojo, manco, ciego, enfermo, etc.") y el mendigo anciano. ${ }^{38}$ Las tipificaciones enunciaron cuatro grandes causas del problema: la mendicidad como institución arraigada en la tradición católica; la mendicidad en relación con las enfermedades, epidemias y deficiencias físicas; la mendicidad respecto de la falta de trabajo y el alcoholismo, y por último, la mendicidad como consecuencia de la desadaptación y desorganización de la familia. Las múltiples causas de la mendicidad relacionadas con la forma de la pobreza urbana encontraron sus explicaciones en cuatro aspectos generales: la incapacidad física para laborar (enfermedades, curables e incurables), el deterioro social para integrarse a la vida productiva (carencia de redes de apoyo), la vulnerabilidad en ciertos periodos del ciclo de vida (infancia, ancianidad, maternidad) y la condición económica frágil (salarios insuficientes y desempleo).

\section{a) "Incapacitados" y desvalidos}

Quienes merecieron asistencia, según esta clasificación, de manera legítima, fueron las personas con discapacidades físicas, transitorias o permanentes que, por accidente o por enfermedad, tenían disminuida su capacidad para laborar. Lo mismo se aplicó a los niños pobres, "los inválidos", los enfermos y los ancianos, quienes obtuvieron cierta legitimación inmediata para recibir auxilio en las escuelas, asilos y hospitales públicos.

Respecto de la incapacidad física para laborar y la vulnerabilidad en ciertos periodos del ciclo de vida, Beteta y Simpson

\footnotetext{
${ }^{38}$ BeteTA, La mendicidad, p. 121. Cada caso de estudio fue descrito minuciosamente destacando en ellos los atributos distintivos de la tipificación a que se recurrió; también, a la representación fotográfica de los mendigos elegidos para el reconocimiento de estos atributos. Si bien la ficha de los mendigos contaba con un recuadro para anexar una fotografía, "el retrato burocrático" para identificar a los pobres no se utilizó como filiación y control del Estado.
} 
sentaron las pautas para mostrar que la mendicidad era una manifestación de los efectos del empobrecimiento, que suscitaba la enfermedad desatendida de los indigentes y la desprotección de los ancianos y los niños pequeños, los ciegos, los sordos, los mutilados o los enfermos psiquiátricos.

La Beneficencia no brindó auxilios para la familia ni asistencia domiciliaria y, con una clara idea del carácter subsidiario del auxilio que brindaría el Estado, supuso que los individuos eran responsables de mantenerse, a ellos y a sus dependientes, y sólo en el caso de que la familia o las redes de parentesco fallaran, el Estado intervendría para ayudar a los individuos en los establecimientos de la Beneficencia Pública. Según el argumento de que era un sistema más eficaz, este modelo de asistencia, que obligaba al internamiento de los indigentes, se fue imponiendo desde finales del siglo XIX en algunos sistemas públicos de ayuda, que además, privilegiaron el auxilio a la necesidad individual sobre las carencias de la familia. ${ }^{39}$

Sobre la base de criterios y saberes profesionales, aunque considerando una oferta restringida de servicios en las instituciones de asistencia social, cada grupo de indigentes recibió ayuda especializada según su clasificación. La relación de los indigentes con el trabajo continuó siendo un parámetro para distinguir a los merecedores de los recursos de la asistencia. ${ }^{40}$

39 Para el caso europeo, Althammer y Stazic-Wendt, "Poverty", pos. 141. En México, la Beneficencia Pública consideró este esquema de ayuda intramuros para la asistencia social desde finales del siglo xix. Lorenzo, Obras. Esto no supuso la supresión de sistemas asistenciales privados y religiosos que funcionaron de manera paralela a la beneficencia del Estado y brindaron ayuda domiciliaria: Arrom, Volunteering. También en el ámbito de programas de salud especiales se consideró la visita domiciliaria: AgOstoni, "Las mensajeras de la salud".

${ }^{40}$ La Junta de Beneficencia evidenció esta condición para exponer el tipo de auxilio que brindaría la institución. AHSS, BP, DG, JD, leg. 6, exp. 6. Como señala Castel, la incapacidad para trabajar es el criterio más importante para definir al merecedor del recurso, así como al depositario de algunos derechos. 
Según la "capacidad" o la "incapacidad” para integrarse a las actividades consideradas productivas, la Beneficencia definió el tipo de auxilio que recibirían los indigentes. De acuerdo con estos criterios, los mendigos que en apariencia estaban "sanos" carecieron de legitimación inmediata para convertirse en merecedores de los recursos de la asistencia.
b) Vagos, alcohólicos, malvivientes...
$y$ los otros que no fueron vagos

En el caso de los alcohólicos y criminales que mendigaban, Beteta y Simpson identificaron este comportamiento con una patología social y, de manera explícita, apuntaron que:

Desde el punto de vista del sociólogo, los pordioseros y la "Institución” de la mendicidad, son fenómenos patológicos. Como el crimen, como la delincuencia juvenil, como la prostitución, la mendicidad representa un desajuste en el funcionamiento normal del individuo y el grupo. Por otra parte, el pordiosero es esencialmente un individuo desmoralizado y desadaptado, y la “institución” de la mendicidad es un síntoma de desorganización social. ${ }^{41}$

Médicos y abogados consideraron a los alcohólicos como un peligro social, aunque creyeron que no era posible declararlos "culpables moralmente". En esta lógica se emitieron normas, códigos y reglamentos pensados para contener este "problema" entre la enfermedad y la delincuencia. ${ }^{42}$

Los mendigos profesionales, considerados vagos, y los delincuentes acusados de "malvivientes" debían confinarse en las

\footnotetext{
Por eso, las personas que pudiendo trabajar, no lo hacían, quedaban privadas de ser atendidas o socorridas de cualquier forma, mientras que las personas que por razones diversas no podían trabajar, debían ser objeto de cuidado e intervención del Estado. CASTEL, Las metamorfosis de la cuestión social, p. 22.

${ }^{41}$ BeteTA, La mendicidad, p. 17.

${ }^{42}$ Pérez Montfort, Tolerancia y probibición, pp. 197-198.
} 
cárceles y reformatorios, pues los recursos de los establecimientos de asistencia, pública y privada, se reservaban para la atención de los pobres necesitados, según las otras causas particulares de su indigencia. ${ }^{43}$ La pertinencia de la intervención del Estado para erradicar la mendicidad se justificó en el entendido de la necesidad de proteger al "cuerpo nacional" y resguardar los comportamientos sociales de las influencias negativas que los mendigos y otros "seres desgraciados" reproducían desde los estratos más bajos de la sociedad, las cuales evidenciaron el atraso social en el espacio urbano. ${ }^{44}$

Entre el vago y el mendigo, la diferencia residió en que el mendigo detentaba ciertas condiciones, como la incapacidad para laborar, que le valían para ser tolerado en la sociedad, cuando menos hasta la segunda década del siglo xx. ${ }^{45}$ No obstante, ante la idea de acabar con la mendicidad, resultó imprescindible asistir a los desvalidos, encerrar a los vagos y plantear alternativas para las personas "sanas" en apariencia que mendigaban en las calles para subsistir. El estudio de Beteta y Simpson, lejos de condenar a este último grupo de pobres al encierro por vagos, ubicó a los "mendigos sanos" que pedían limosna como la manifestación de una patología interconectada con otros problemas como la inmoralidad, la sobrepoblación o la depreciación del estándar de vida a causa de los bajos salarios y el desempleo. Con todo, la porosa diferencia entre unos y otros implicó que, arbitrariamente, algunos indigentes fueran recluidos en las cárceles de la ciudad.

\footnotetext{
43 Beteta, La mendicidad, pp. 122-126.

${ }^{44}$ URÍAs, "Eugenesia e ideas", p. 182.

${ }^{45}$ Esta diferencia se ha estudiado ampliamente en la instauración y el funcionamiento de los tribunales de vagos en el siglo xIX como un momento peculiar del control sobre la indigencia y la pobreza criminalizada. Arrom, "Vagos"; Pérez Toledo, "Los vagos de la Ciudad de México"; Arrom, Para contener al pueblo, p. 283; Araya, "De los límites"; Lida y Pérez Toledo, Trabajo, ocio y coacción.
} 
c) Los "sin trabajo", el empleo ocasional $y$ el salario precario

El resultado de la investigación concluyó que la pobreza era la causa fundamental de la mendicidad y que la supresión del problema, inmerso en la crisis económica, se lograría cuando se mejorara el nivel de vida de la población y se elevaran los salarios. En cuanto a la "condición económica frágil”, se señaló además la necesidad de conceder pensiones de protección en las huelgas, y seguros de vida, salud y vejez. También se instó al gobierno a que se aplicaran las leyes que hicieran efectivo el salario mínimo, entre otras disposiciones que debían mejorar la estructura económica general del país. La Beneficencia Pública recomendó, con base en su estudio de la pobreza, la expedición de una normativa que elevara y asegurara los niveles de vida de la población. Coincidió que, en los años en que se elaboró el estudio de la mendicidad, entre los diputados, y en diversos ámbitos del mundo del trabajo, se discutiera la expedición de la primera Ley Federal del Trabajo, la cual se publicó el 18 de agosto de 1931.

La Ley Federal del Trabajo cumplió con algunas demandas de los sindicatos; no obstante, la relación entre el Estado social y los obreros perfiló que la seguridad social estuviera ligada al contrato de trabajo ${ }^{46}$ Había confianza en que la regulación de las relaciones de trabajo garantizaría el cumplimiento de los derechos sociales para los trabajadores, tal como lo señalaron Beteta y Simpson en su estudio de la mendicidad. El sistema corporativo de seguridad social para los trabajadores quedó sujeto a las disposiciones de las leyes del trabajo, en tanto que la Beneficencia reconoció sus límites y focalizó su atención a la

${ }_{46}$ ZaPATA, El sindicalismo, p. 112. Respecto de la coalición institucional entre los obreros y el Ejecutivo en el marco de la expedición de la Ley Federal del Trabajo, véase Dion, Workers, pp. 30, 58-59. 
protección social para los considerados enfermos, incapacitados y desvalidos.

El desempleo, como una condición frágil ante la crisis, implicó una atención diferenciada dentro del amplio espectro de la protección a la pobreza. Pero, en México, la categoría de desocupado o desempleado no supuso el reconocimiento explícito o inmediato de merecedor de la asistencia pública; cuando menos no sucedió así durante los años treinta del siglo xx.

La precariedad del salario de algunos mendigos también fue una condición que reconocieron Beteta y Simpson como causa del deterioro de la vida de las personas, pero sobre la cual la Beneficencia tampoco presentó como el medio para brindar soluciones efectivas; instaron al gobierno para que buscara respuestas alternativas, como seguros de vida y de trabajo.

Según sustentaron Beteta y Simpson, la Beneficencia Pública carecía de la capacidad para atender a los “sin trabajo”, y sus recursos, destinados al auxilio de la indigencia de los desvalidos, no podían desviarse para solucionar el problema de la precariedad laboral. ${ }^{47}$ En este sentido, los pobres “sanos”, aptos para el trabajo, tendrían que encontrar otros medios distintos del auxilio de la Beneficencia para paliar sus condiciones de pobreza.

Respecto de la intervención del gobierno para paliar la indigencia de las personas aptas para laborar que mendigaban en las calles, las trabajadoras sociales denunciaron las paupérrimas condiciones de vida de los indigentes que no encontraban alivio en las medidas impulsadas por los gobiernos. ${ }^{48}$ En sus reportes de

${ }^{47}$ La capacidad de atención era limitada: de las 74 instituciones de beneficencia, sólo 18 pertenecían a la Beneficencia Pública; las 56 restantes dependían de fundaciones y asociaciones. AHSS, BP, DG, Actas de Sesión, lib. 6, 1930. Los objetivos de estas instituciones se abocaban a la atención de salud, educación y asilo, y se focalizaban a ciertos grupos de destinatarios, entre los cuales no se consideró de manera específica a los desempleados.

${ }^{48}$ Del compromiso de transformación social en la formación de las trabajadoras sociales en México, SANDERs, Gender and Welfare, pp. 121-133; EvANGELISTA, Historia del trabajo social. 
entrevista con los mendigos, ellas reconocían la incapacidad del gobierno para brindar oportunidades de trabajo y elevar los salarios precarios que percibían los indigentes. Por ejemplo, la inspectora M. L. Doherty apuntó, como resultado de una de sus entrevistas, entre el reclamo y la nostalgia: "lástima que el gobierno no tiene un trabajo en que emplear gentes así [sic], sano, fuerte, de aspecto honrado; algo de tipo 'morón', pobre y sin trabajo". ${ }^{49}$ En este caso, el mendigo que había sido trasladado a la cárcel por error fue liberado, pero no recibió de la Beneficencia ayuda o auxilio para solventar su condición de miseria.

El estudio de la mendicidad resultó en un diagnóstico empírico que coincidió con el proyecto de acción social de una amplia "revolución cultural”, la cual buscó inculcar nuevos valores cívicos frente "al poder de la Iglesia católica” ${ }^{50}$ También fue un espacio para acusar a la Iglesia católica y justificar la persistencia de la mendicidad en México. Así, la responsabilidad del gobierno se diluyó bajo el argumento de que la tradición católica de dar limosna era la causa principal de la institucionalización de la mendicidad: los hombres y mujeres "sanos" mendigaban porque, según se expuso, vivir de limosnas estaba arraigado en una sociedad donde la actitud caritativa de los católicos fomentaba evitar el trabajo. ${ }^{51}$

Aunque desde finales del siglo xIx, en el contexto de una reforma inspirada en el catolicismo social, las organizaciones de la Iglesia promovieron la idea de que la limosna para los pobres era una dádiva improductiva, el estudio de Beteta insistió en que la Iglesia y su tradición eran responsables de institucionalizar la mendicidad. ${ }^{52}$ Además de reconocer las desventajas de esta forma de ayuda, Beteta señaló que la intervención efectiva de la

\footnotetext{
49 AHSS, BP (octubre de 1930).

50 URÍAs, “Locura y criminalidad”, p. 348.

51 Beteta, La mendicidad, p. 49.

${ }^{52}$ Este recurso argumentativo sobre la limosna había sido una justificación recurrente de los benefactores del Asilo Particular de Mendigos ante la
} 
sociedad consistía no sólo en extirpar la tradición de la limosna, sino en sumarse a los propósitos del Estado de regenerar a los mendigos y convertirlos en ciudadanos útiles para acabar definitivamente con la mendicidad. También es cierto que la influencia subyacente del protestantismo liberal tuvo gran peso en la conformación del grupo de estudiosos de la mendicidad por medio de Moisés Sáenz. Esta influencia permeó la labor de los sociólogos de Chicago, como Simpson, en el estudio de la mendicidad y coincidió con el discurso de un Estado laico y anticlerical que sustentaba Beteta. ${ }^{53}$

\section{d) Asistencia social y seguridad social}

En el estudio de la mendicidad, reconocieron que, en ciertos ciclos de la vida, las personas mendigaban en las calles para sostener a sus hijos pequeños o cuando su avanzada edad limitaba sus capacidades para trabajar. Distinguieron a estos pobres de los “degenerados" porque, en el caso de los primeros, en tiempos de crisis, según señaló la investigación de Beteta y Simpson, la mendicidad era un recurso extremo que algunos pobres practicaban para enfrentar las condiciones económicas críticas del mercado. También, en el estudio de la mendicidad, se diferenció a los pobres considerados "mendigos sanos", pero transgresores, de aquellos “mendigos sanos” que carecían de empleo o que percibían salarios muy precarios y que pidieron limosnas, de manera ocasional, mientras conseguían empleo o bien para paliar la condición lábil de sus familias.

El estudio de Beteta y Simpson no obvió que México había resentido algunos efectos relacionados con los antecedentes de la crisis económica, y la investigación expuso un recuento de

persistencia de pordioseros en las calles a finales del siglo xIx. Lorenzo, "Los mendigos", p. 359.

53 Wallerstein, El moderno sistema mundial, p. 357. Bastián, Los disidentes, p. 308. 
desempleados por sectores productivos desde 1928. Con base en los datos del Departamento del Trabajo, calculaban que había 23500 personas sin trabajo, las cuales se concentraban, por ocupación, en el grupo de operarios, obreros y "contratistas en pequeño" ${ }^{54}$ Aun con la exhibición de estos datos: las restricciones del mercado laboral, el despido de trabajadores en ciertos sectores de la industria o la repatriación de miles de trabajadores mexicanos de Estados Unidos, el estudio de la mendicidad mostró que estas condiciones fueron, entre otras - como la enfermedad, las deficiencias físicas, el alcoholismo y "los efectos desorganizantes de la vida citadina" - , las causas que explicaron la mendicidad en México. Beteta y Simpson expusieron, de manera incisiva, que la Beneficencia no era el ámbito que resolvería el problema de las condiciones de pobreza en las que vivía el grueso de la población que habitaba en la ciudad de México. La Beneficencia sólo podía ocuparse de aquellos indigentes sobre los cuales podía incidir de manera eficaz.

La política social diseñada para acabar con la mendicidad tuvo el propósito de ir "absorbiendo lentamente dentro del seno social a los seres desadaptados, educando a unos en nuestras escuelas, empleando a otros en nuestros talleres, curando a los de más allá en nuestros hospitales, internando en establecimientos de caridad a los que no tengan otro remedio" ${ }^{55}$ Respecto de los desempleados, de los que tenían salarios muy precarios o de los que tenían trabajos temporales y mendigaban para paliar sus condiciones de vida, la Beneficencia sugirió que el gobierno ideara reformas estructurales que impulsaran el desarrollo económico y que los sectores productivos mejoraran el nivel de vida en México.

\footnotetext{
${ }^{54}$ Beteta, La mendicidad, p. 75. De acuerdo con el Quinto Censo de Población, 1930, la población masculina sin trabajo era de 13995 personas. BETETA, La mendicidad, pp. 74-75. Ríos, "La psicosis del repatriado", p. 369. En otras instituciones de asistencia, como el Manicomio General, se registró el ingreso de internos repatriados de Estados Unidos.

${ }^{55}$ BetetA, La mendicidad, p. 127.
} 
En suma, a partir del estudio de la mendicidad elaborado por la Beneficencia Pública, distinguimos tres grandes aspectos en los cuales la intervención del Estado se propuso abatir esta forma de pobreza urbana y caracterizó los objetivos diferenciados de la política social entre 1929 y 1931. En primer lugar, aunque limitada para ciertos grupos, la Beneficencia se encargó de los niños pequeños, los inválidos, los enfermos, los ancianos y de los incapacitados para el trabajo, quienes debían acudir a las instituciones públicas de asistencia para ser atendidos. En segundo lugar, para proteger a las personas "sin trabajo" y mejorar las condiciones de vida de los que percibían salarios precarios y que carecían de elementos o ayuda para conseguir empleo o superar su indigencia, el Estado debía fomentar su incorporación en los sectores productivos del país, con el impulso al desarrollo económico de la industria y el campo. Además, debía procurar el incremento del salario de los trabajadores y asegurar sus condiciones de vida ante diversos riesgos como accidentes o desempleo. En tercer lugar, la reclusión en las cárceles y reformatorios siguió vigente como una forma de intervención hacia las personas capacitadas para el trabajo, que por falta de voluntad no lo realizaban. Los mendigos "profesionales" quedaron excluidos de la asistencia del Estado. El encierro en las cárceles fue el destino más eficaz que se pensó para la corrección de vagos y malvivientes.

\section{LA PROTECCIÓN SOCIAL: ¿QUÉ HACER CON LOS MENDIGOS?}

Para algunos sociólogos, el progreso y el restablecimiento del orden eran el corolario de la imposición de las reglas y las normas en una sociedad moderna que se percibió como desorganizada. La modificación del marco jurídico fue una reforma sugerida por Beteta sin la cual, según su visión, el Estado no podría erradicar la mendicidad. En relación con las propuestas de los juristas, que concedieron al Estado el monopolio de la 
creación y la aplicación de la ley, ${ }^{56}$ la reforma al Código Penal era imprescindible para acabar con los limosneros. Enfáticamente, Beteta y Simpson argumentaron la conveniencia de prohibir la mendicidad en todos los casos sin distinguir "entre las gentes que lo necesiten y las que no". La derogación del Código Penal de 1929 y su nueva redacción se llevó a cabo durante la campaña contra la mendicidad, lo cual indica que pudo haber interés de los estudiosos del problema social por incidir en una disposición normativa que prohibiera la mendicidad..$^{57}$

En cuanto a los procedimientos para acabar con la mendicidad, Beteta y Simpson recomendaron evitar las razias organizadas por la policía para "levantar" de la calle a los mendigos. Reprobaban esta práctica, pues según el diagnóstico de la mendicidad, la intervención violenta de la fuerza policiaca en la recolección de mendigos no conducía hacia el abatimiento efectivo de este tipo de pobreza en las calles, lo cual se fundamentó en los resultados fallidos de las experiencias del pasado.

Esta disposición, que a simple vista se percibía como compasiva, implicó una reforma administrativa y el desplazamiento de las atribuciones de la policía de la ciudad, que había recogido a los mendigos como parte de las atribuciones cotidianas de seguridad y de ordenamiento urbano desde mediados del siglo xIX.

Como alternativa al encierro de los mendigos, el procedimiento de estudiar a los pordioseros de manera individual y brindar la solución más adecuadas a su situación era "lento", implicaba "la existencia de personal técnico" y representaba una inversión de "dinero". Eso lo reconocieron Beteta y Simpson. No obstante, insistieron en que la solución al problema tendría resultados efectivos y certeros. Es de notar también que, con este

\footnotetext{
${ }^{56}$ Del legalismo jurídico, sus críticas y adaptación del porfiriato a la posrevolución, véase SpeckMan, "Los jueces”, p. 1426.

${ }^{57}$ Las disposiciones del Código Penal sobre los mendigos y su aplicación suscitaron que en 1932-1933 el número de mendigos recogidos se intensificara. OchOA, “Coercion, Reform”, p. 46.
} 
procedimiento, los trabajadores sociales, encargados de "saber con precisión lo que necesitan" los pobres y los desafortunados, se colocaron en el eje de la reforma asistencial para el tratamiento de la mendicidad. ${ }^{58}$

Moisés Sáenz impulsó el estudio de la mendicidad en México, pero también reconoció los límites materiales que la Beneficencia Pública del Distrito Federal tenía para emprender una incursión sistemática del Estado sobre la población indigente. Sin duda, el diagnóstico científico respecto de los problemas sociales fue un aval, cada vez más significativo, para ponderar la viabilidad de los proyectos que el Estado impulsó para atender problemas sociales. ${ }^{59}$ No obstante, el pragmatismo político y la administración pública se impusieron como contraparte en el diseño de la campaña contra la mendicidad.

Sáenz procuró acercarse al escenario ideado por Beteta y Simpson e intentó conseguir recursos para mejorar las condiciones de escuelas, asilos y hospitales que darían cabida a mendigos. En un acucioso informe dirigido al presidente Ortiz Rubio, Sáenz describió de cuántas maneras la Beneficencia carecía de la capacidad para atender a los mendigos, y solicitó un incremento en el presupuesto asignado a la campaña. Sáenz expuso que los recursos eran limitados para cubrir los gastos diarios que erogarían la recolección, la limpieza general y la clasificación de los mendigos. ${ }^{60}$ Para solventar estos gastos, Moisés Sáenz presentó

${ }^{58}$ Beteta, La mendicidad, p. 125.

59 Tenorio, "Stereophonic", p. 1169. Al proceso de adecuación que los científicos mexicanos hicieron de los métodos de las ciencias sociales importadas de Estados Unidos, Tenorio lo denominó “mimetismo pragmático", por el diálogo que iniciaron con las ideologías cosmopolitas y por la coincidencia con los intereses políticos de la época (1920-1930).

${ }^{60}$ AHSS, BP, AS, DAES, leg. 1, exp. 11, ff. 297-298. “Algunas sugestiones que se estimen pertinentes para poder llevar a la práctica el proyecto del C. Presidente de la República, sobre los mendigos”, AHSS, BP, DG, Actas de Sesión, lib. 6 (1930), p. 94. "Sobre las condiciones de la Beneficencia Pública y las posibilidades de esta institución para contribuir a la erección y sostenimiento del 
al presidente de la República un plan para crear un "patronato" en el que la Beneficencia Pública colaboraría con la Beneficencia Privada, para acondicionar una especie de granja donde los pordioseros recibirían el tratamiento adecuado para su reintegración a la sociedad. ${ }^{61}$ Esta especie de granja-albergue aliviaría la falta de infraestructura para la atención de los pobres y los prepararía para la vida productiva. Sin embargo, el Ejecutivo rechazó la propuesta del patronato. ${ }^{62}$

Con todo, la campaña se inició, aunque sin la infraestructura ideada por el estudio de la Beneficencia para brindar asilo a los mendigos. Para atender de manera temporal a los mendigos que la policía tomaba para clasificarlos, la Beneficencia acondicionó uno de los dormitorios públicos de la ciudad. A partir de ahí, el tratamiento especializado lo recibirían en los hospitales, casas, asilos y escuelas de la Beneficencia Pública del Distrito Federal.

La Beneficencia también acomodó a sus posibilidades la idea de los científicos sociales respecto de la intervención de la fuerza policiaca en la tarea de recoger a los mendigos de la calle, pues si bien el estudio de Beteta señaló que las incursiones violentas organizadas por la policía no llevaban por el camino efectivo, en octubre de 1930, "a golpe de porra", la policía recogió a los mendigos de las calles, con lo cual dio inicio la razia contra los pordioseros..$^{63}$

Aunque la Beneficencia quiso asumir el control de esas acciones para modernizar la acogida de los pobres, no contó con el personal especializado para levantar a los pordioseros de las

nuevo Asilo de Mendigos.” Se calculó que el gasto sería de 200 pesos diarios.

${ }^{61}$ AHSS, BP, DG, Actas de sesión, lib. 6 (1930). El capital lo aportarían las beneficencias, pública y privada, “en dinero, en propiedades raíces y en créditos”, y calculaban una cantidad de 35000 pesos.

${ }^{62}$ AHSS, BP, DG, JD, lib. 6, f. 124. Telegrama Pascual Ortiz Rubio a Moisés Sáenz y firmantes, 21 de agosto de 1930.

${ }^{63}$ La contradicción entre el proyecto y la acción policiaca también llamó la atención de Alanís, "La niñez desvalida”, pp. 74-75. 
calles. Además, careció incluso de vehículos suficientes para trasladarlos a los lugares destinados por la Beneficencia y tuvo que emplear los recursos disponibles que proveyó la Jefatura Central del Distrito Federal para recoger a los pordioseros.

Cabe destacar que los policías no debían trasladar directamente a los mendigos de la calle a la cárcel. El traslado de los indigentes a los espacios de reclusión, en teoría, debía estar mediado por el proceso de clasificación de los inspectores de la Beneficencia. Esta acción quizá no fue del todo eficaz, pero sí se pensó como una forma de humanizar el trato a los pobres y, en la práctica, durante la incursión de la policía, menos de 10\% del total de los mendigos clasificados fueron ingresados en la cárcel municipal (véase la tabla 1).

\section{Tabla 1}

DISTRIBUCIÓN DE MENDIGOS EN ESTABLECIMIENTOS

ASISTENCIALES Y CARCELARIOS, 1931

\begin{tabular}{lr}
\hline Hospital Homeopático & 2 \\
Hospital Juárez & 4 \\
Casa de Cuna & 6 \\
Escuela Industrial & 8 \\
Escuela de Ciegos & 22 \\
Hospital General & 27 \\
Cárcel del Carmen & 27 \\
Manicomio General & 31 \\
Casa del Niño & 36 \\
Asilo de la Beneficencia Pública & 50 \\
Asilo Nicolás Bravo & 97 \\
Total & 310 \\
\hline
\end{tabular}

FuENTE: AHSS, BP, AS, DAES, leg. 2, exp. 6, 1-9, febrero 27, 1931. De los 323 recogidos y registrados por la Beneficencia Pública, se señaló que 13 de ellos no estaban clasificados, por lo cual no se cuantificaron en esta tabla. 
En los primeros días de octubre de 1930, la noticia de la incursión organizada por la policía contra los mendigos tuvo una amplia difusión en la prensa. En contraposición a las recomendaciones de la Beneficencia, el coronel Eduardo Hernández Cházaro, secretario particular de Ortiz Rubio, dictó la orden de "dar un golpe de muerte a la mendicidad callejera". En estos términos, la prensa anunció el inicio de la campaña que debía “capturar" a los pordioseros que pululaban en las calles de la ciudad "para impresionar al público con sus harapos y su miseria". ${ }^{64}$ Se supuso que el "miedo" que provocó la redada de los policías entre los pobres avalaba la efectividad de la acción del gobierno de la ciudad. Para darle rostro al "enemigo", entendido como una "plaga social”, El Universal criminalizó el comportamiento de estos grupos de indigentes y "confirmó" la existencia de una "mafia organizada de mendigos" que eludía la persecución orquestada por el Departamento Central del Distrito Federal..$^{65}$

La coexistencia de discursos tan antagónicos sobre el tratamiento de la mendicidad se aprecia en el lenguaje que utilizaron la prensa y Beteta y Simpson en el diseño de una política social que reprobó el uso violento de la fuerza policiaca contra los indigentes. Atributos como el de personas "desorganizadas", "desmoralizadas" o "faltas de adaptación social" resignificaron la mendicidad, a partir de una taxonomía que apeló a referencias relacionadas con la idea de patologías sociales. En cambio, la prensa y los policías emplearon vocablos como "razia", "captura de mendigos", "centros de concentración", "plaga de harapientos" y "leva", para referirse a las incursiones del Estado en la campaña contra la mendicidad. Nombrar a los "pordioseros", "menesterosos", "limosneros" y mendigos no fue una manifestación de la complejidad semántica del mundo de la pobreza,

64 "Medidas enérgicas contra la mendicidad en la metrópoli”, El Universal (7 oct. 1930), pp. 1-7.

65 "Seguirá la ofensiva contra los mendigos", El Universal (9 oct. 1930), pp. 1, 6 . 
sino la oposición a términos peyorativos y denigratorios que revelaban distintas maneras de atender un mismo problema por actores antagónicos. Asimismo, refleja la forma como se fue construyendo el conocimiento experto sobre la miseria.

En una postura intermedia, Moisés Sáenz tuvo la habilidad de acomodar las acciones policiacas organizadas por la Jefatura del Distrito Federal a la propuesta de la Beneficencia, y reelaboró un discurso que retomó algunas observaciones del proyecto de Beteta y Simpson, en el que enfatizó que la acción de la Beneficencia la sustentaba el saber técnico científico. Unos cuantos días después del inicio de la campaña, Sáenz declaró a Excelsior que:

Enemigo como soy de la violencia, me alegra, sin embargo, el que se haya podido limpiar a la ciudad de un considerable número de mendicantes y estoy decidido a poner en juego todos los recursos, técnicos y administrativos de la beneficencia, para resolver en forma tan inteligente y humana como sea posible el problema de esta gente, por lo general desadaptada [...] Aunque en términos generales me parece inadecuado el procedimiento de redada empleada para con los mendigos [...] la Beneficencia Pública aprovecha esta oportunidad de tener juntos a buen número de mendigos para emprender, dentro de una verdadera técnica, el estudio de cada caso [...] forma ésta que es, en mi sentir, la más juiciosa y humana. ${ }^{66}$

Excelsior precisó que el Departamento de Acción Social, a cargo de Ramón Beteta, se ocuparía de formar las comisiones de selección con los investigadores sociales que habían participado en el estudio de la mendicidad, para cumplir con la labor asistencial del Estado. En el dormitorio público número 2 de la calle de Cuauhtemotzin, dependiente de la Beneficencia, los hombres y las mujeres recogidos por la policía recibieron ropa y alimento en una gran galera divididas en dos que separó a los

${ }_{66}$ "El problema de los mendigos va a ser estudiado", Excelsior (11 oct. 1930), p. 6. 
mendigos por sexo durante el proceso de limpieza general y de clasificación. ${ }^{67}$

Desde los primeros días de la campaña, el dormitorio resultó insuficiente. El Universal expuso que, para el confinamiento de los pordioseros, el Departamento Central estaba dispuesto a “tomar providencia y acondicionar un bodegón” en la cárcel Preventiva Municipal, además de construir "cuantas barracas fueran necesarias", en el entendido de que era preferible "trabajar para alimentar y alojar a los mendigos que tener que soportarlos estoicamente en las calles cuando estamos en la obligación de evitarlos". ${ }^{68}$

Por su parte, los miembros de la Junta de Beneficencia expusieron que acondicionarían un terreno en Tlalpan para alojar una colonia de mendigos, clasificados como aptos para trabajar, donde éstos podrían cultivar una huerta y laborar en diversos talleres de oficios. Entre tanto, los asilos y hospitales brindarían servicio a los mendigos enfermos. ${ }^{69}$

Pese a las condiciones de encierro y liberación, la prensa insistió en que la campaña tenía un sentido asistencialista y denotó el carácter residual de la ayuda que brindó la Beneficencia. Así, Excelsior destacó que: "para que el público pudiera formarse idea del efecto saludable que ha producido la acción gubernativa y de la Beneficencia Pública, es de considerarse el hecho de que varios mendigos se han presentado espontáneamente en las oficinas de la misma Beneficencia, pidiendo ser internados

${ }^{67}$ En los primeros días de campaña, la comisaría de la cárcel municipal del Carmen y el Hospital Homeopático, además del dormitorio público número 2 , se utilizaron como espacios de concentración de mendigos. Después de 1931, sólo el dormitorio público número 2 funcionó como casa de concentración.

68 "Medidas enérgicas contra la mendicidad", El Universal (7 oct. 1930), pp. 1,7 .

69 "Seguirá la ofensiva contra los mendigos", El Universal (9 oct. 1930), pp. $1,6$. 
en el Asilo de Ancianos". ${ }^{70}$ Desde la lógica de la subsistencia, los pobres acudieron voluntariamente a los establecimientos de la Beneficencia, sobre todo cuando brindaron algunos auxilios como techo, alimento o vestido. ${ }^{71}$ Con todo, el ingreso voluntario de los pobres en las instituciones de asistencia no se expuso en la prensa como una evidencia de la necesidad o de la precariedad de los indigentes, sino como prueba de la benevolencia del Estado.

Según expuso Moisés Sáenz:

La [Beneficencia] Pública, como un acto de cooperación, está recogiendo a las gentes, las estudia y clasifica y además de darles albergue y ropa durante todo este tiempo, pasarán ya depurados en su carácter de mendigos, al asilo especial para ellos [de la Beneficencia Privada]; porque hay muchos que se recogen y que deben ir al Hospital, otros al Manicomio, otros a la cárcel, etc. Esta clasificación se ha ido haciendo a medida que se van recogiendo poco a poco, para no hacer razias violentas; podríamos ir más deprisa de lo que vamos, pero tampoco hemos querido sobrecargarnos en la Pública de mucha gente. De modo que creemos que ya pronto podrán pasarse todos estos mendigos al Asilo hasta completar el cupo de esta nueva institución que será de $300 .{ }^{72}$

La contradicción entre las incursiones violentas y los procedimientos recomendados por el estudio de la mendicidad, no fue un impedimento para valorar la utilidad de la investigación, que se traducía en resultados prácticos y no se quedaba "como simple investigación científica pura”. Beteta afirmó que:

\footnotetext{
70 "Pueden visitar a los mendigos sus familias y aun sacarlos libres", Excelsior (11 oct. 1930), pp. 1-6.

71 De la voluntariedad del ingreso y los usos de la asistencia de los indigentes. Lorenzo, “Los indigentes”, pp. 222-228; Lorenzo, “Los mendigos”, p. 346. 72 “Acta de la sesión ordinaria que celebró la Junta Directiva de la Beneficencia Pública del Distrito Federal, el día 11 de abril de 1931”, AHSS, BP, DG, Actas de sesión, exp. 6.
} 
La investigación sirvió además, para despertar e iluminar a la opinión pública sobre las causas de la mendicidad y sus varios aspectos y al mismo tiempo para cambiar la actitud de las gentes y de los periódicos respecto de estas cuestiones sociales, haciéndoles comprender que se trata de fenómenos complejos que no pueden ser resueltos sin estudio. ${ }^{73}$

Es de notar que, durante la campaña contra la mendicidad, la policía detuvo en calidad de mendigos a 644 personas, de las cuales la mitad fueron liberadas porque, según la mirada de los nuevos expertos, los inspectores de la Beneficencia no los consideraron mendigos. Eso supuso que una mirada distinta de la policial pudo definir el destino de aquellos que parecían mendigos, y que fueron recogidos y trasladados a los espacios destinados para su concentración, sólo según su apariencia. Carecemos de datos de este grupo de "liberados", pero con base en estas apreciaciones es probable que formaran parte del grupo de los "sin trabajo", desempleados o con salarios precarios.

En cuanto a la atención social hacia los mendigos, de los 310 detenidos y clasificados por los inspectores de la Beneficencia, 91\% recibieron algún tipo de asistencia en los hospitales, escuelas y asilos de la Beneficencia, y solo 9\% restante ingresó en la cárcel municipal. Según se muestra en la tabla 1, durante esta incursión de la Beneficencia, la atención especializada hacia los mendigos concibió el problema de la mendicidad como parte de la protección a los grupos desvalidos, más que como una cuestión de seguridad y ordenamiento policial.

La labor de Moisés Sáenz al frente de la Beneficencia Pública contó con el aval de los resultados estadísticos y el saber de los científicos sociales, aplicado y ajustado, para brindar soluciones al problema de la mendicidad. No obstante, el 13 de junio de 1931, Moisés Sáenz fue destituido de la dirección de la Beneficencia Pública y Francisco Ortiz Rubio, hermano del presidente

${ }^{73}$ AHSS, BP, AS, DAES, leg. 11, exp. 11. 
de la República, ocupó su lugar. ${ }^{74}$ Durante el año que Ortiz Rubio dirigió la Beneficencia se suspendieron las campañas contra los mendigos, pero se reanudaron a finales de 1932. A lo largo de la década hubo otras incursiones de la policía que fueron modificando los procedimientos ideados por los científicos sociales y, en la práctica, la Beneficencia se ajustó a las necesidades que dictó el gobierno de la ciudad, que intensificó el carácter coercitivo sobre la pobreza mendicante.

\section{CONCLUSIONES}

Este artículo centró su atención en las acciones que el Estado mexicano impulsó para mitigar un problema relacionado con la pobreza urbana en la ciudad de México.

La mendicidad se asoció a la pobreza, la falta de trabajo, la precariedad del salario y la incapacidad, física o mental, para laborar; la mendicidad también se relacionó con algunos comportamientos sociales, considerados delictivos, que amenazaban el orden y la seguridad en la ciudad. Para quienes incidieron en el diseño y la ejecución de las campañas contra la mendicidad, las causas que explicaron estas condiciones definieron el problema social de acuerdo con los métodos y los conceptos que las ciencias sociales preveían como instrumentos del conocimiento.

\footnotetext{
${ }^{74}$ Moisés Sáenz presentó al jefe del Departamento su renuncia como vocal de la Junta, la cual fue aceptada y promovida por el presidente de la República. No sabemos con precisión en qué medida la destitución de Sáenz estuvo motivada por la confrontación de un proyecto asistencial opuesto al del Ejecutivo, ni tampoco podemos afirmar que la campaña contra los mendigos tuviera un impacto directo en la destitución de Sáenz. Sin embargo, por el juego de actores involucrados, estas campañas protagonizaron las disputas entre la Beneficencia Pública, el Departamento Central (Distrito Federal) y el Gobierno Federal. Acta de la sesión ordinaria que celebró la Junta Directiva de la Beneficencia Pública del Distrito Federal, el día 11 de junio de 1931. AHSS, BP, DG, Actas de Sesión, leg. 6, exp. 2.
} 
La mendicidad era un tipo específico de miseria urbana. No todos los pobres eran mendigos y, en una sociedad industrializada, la mendicidad se perfiló no sólo como problema urbano, como lo fue en el siglo XIX, sino político y económico. Este tipo de pobres le costaban al Estado recursos, no sólo en su promoción social, sino en una masa de posibles obreros que dejaban de producir. El problema de carácter social y económico lo transformó en un asunto político de primera línea para el Estado, al que acudieron los expertos sociales y se internacionalizaron los saberes y el debate sobre la pobreza urbana y la mendicidad.

La reconfiguración de lo que se entendió por pobreza, a partir de una concepción de la vulnerabilidad de los enfermos, discapacitados y desvalidos, fue el referente en el proceso de clasificación que las trabajadoras sociales que se incorporaron como agentes de la asistencia en la campaña contra la mendicidad. El diagnóstico y la caracterización científica de las condiciones de pobreza dieron la impresión de que se avanzaba, pero en sus soluciones, la práctica asistencial recurrió al auxilio que se preveía para estos pobres en asilos, hospitales y escuelas desde el siglo xix. Así, las propuestas de granjas-taller, o bien de colonias para mendigos, no se concibieron como opción renovada de asistencia para el abatimiento de la mendicidad desde el Estado.

Para acotar el tipo de protección a los pobres que vivían en condiciones miserables, aunque trabajaban, porque sus salarios eran insuficientes para subsistir, o bien para los desempleados, una renovada manera de entender la pobreza afirmó que estas condiciones eran ajenas a la actitud del individuo, el cual se veía afectado por un mercado laboral limitado y los bajos salarios. Ante estas condiciones que afectaron a los pobres de la ciudad, la Beneficencia instó al gobierno a dictar medidas que modificaran estructuralmente el deterioro de la vida de los trabajadores.

En la década de 1930 en México, las políticas públicas que sentaron las bases del Estado social no arrogaron una definición nítida y diferenciada entre seguridad social y asistencia social. 
No obstante, en este trabajo, exploramos cómo en el contexto de la campaña contra la mendicidad se fueron distinguiendo, por un lado, a los trabajadores, que por ley se convirtieron en depositarios de la seguridad social y que consiguieron la garantía de algunos derechos con base en cuotas o aportaciones, además de la relación contractual entre trabajador y empleador, y por otro a los pobres, que debían exhibir un caudal de carencias, entre ellas la falta de trabajo, para recibir auxilios de carácter residual, que el Estado otorgó a los indigentes, usualmente estigmatizados por la asistencia, como merecedores de los servicios de asilo, educación y salud.

Los recursos de la Beneficencia resultaron insuficientes para corregir las condiciones de este grupo de pobres en una economía en crisis. Quizá éste fue el punto de partida para que los gobiernos de la posrevolución, sobre todo durante el sexenio de Cárdenas, sentaran los cimientos de las grandes instancias públicas de protección social, como el Instituto Mexicano del Seguro Social, que colocó en el centro de sus políticas a los trabajadores. Quedaron rezagados los mendigos y el grupo de pobres desvalidos, de estas políticas públicas. Asimismo, quizá de manera más nítida, en esta campaña se reconoció el objetivo diferenciado de la asistencia social al desvalido respecto de la seguridad social que brindó el Estado a los trabajadores.

\section{SIGLAS Y REFERENCIAS}

AHSS, BP Archivo Histórico de la Secretaría de Salud, Beneficencia Pública, Ciudad de México.

AHSS, BP, AS, DAES Archivo Histórico de la Secretaría de Salud, Beneficencia Pública, Asistencia Social, Departamento de Acción Educativa y Social, Ciudad de México.

AHSS, BP, D, AS Archivo Histórico de la Secretaría de Salud, Beneficencia Pública, Dirección, Asistencia Social, Ciudad de México.

AHSS, BP, DG, AS Archivo Histórico de la Secretaría de Salud, Beneficencia Pública, Dirección General, Actas de Sesión, Ciudad de México. 
AHSS, BP, DG, JD Archivo Histórico de la Secretaría de Salud, Beneficencia Pública, Dirección General, Junta Directiva, Ciudad de México.

Аввотт, Andrew, Department and Discipline: Chicago Sociology at One Hundred, Chicago, University of Chicago Press, 1999.

Agostoni, Claudia, Médicos, campañas y vacunas: la viruela y la cultura de su prevención en México, 1870-1952, México, Universidad Nacional Autónoma de México, Instituto de Investigaciones Dr. José María Luis Mora, 2016.

Agostoni, Claudia, "Médicos rurales y medicina social en el México posrevolucionario (1920-1940)", en Historia Mexicana, LXIII: 2 (250) (oct.-dic. 2013), pp. 745-801.

Agostoni, Claudia, "Las mensajeras de la salud. Enfermeras visitadoras en la Ciudad de México durante la década de los 1920", en Estudios de Historia Moderna y Contemporánea de México, 33 (ene.-jun. 2007), pp. 89-120.

Agostoni, Claudia y Elisa Speckman Guerra (eds.), De normas y transgresiones. Enfermedad y crimen en América Latina (1850-1950), México, Universidad Nacional Autónoma de México, 2005.

Alanís Rufino, Celia Mercedes, "La niñez desvalida y las campañas contra la mendicidad en la Ciudad de México en la década de 1930", en Antropología. Boletin Oficial del Instituto Nacional de Antropología e Historia, 98 (2014), pp. 71-85.

Althammer, Beate y Tamara Stazic-Wendt, "Poverty and Endangered Social Ties: An Introducction”, en Althammer, Raphael y Stazic-Wendt (eds.), 2016, pp. 118-636.

Althammer, Beate, Andreas Gestrich y Jens Gründler (eds.), The Welfare State and the "Deviant Poor" in Europe, 1870-1933, Londres, Palgrave Macmillan, 2014.

Althammer, Beate, Lutz Raphael y Tamara Stazic-Wendt (eds.), Rescuing the Vulnerable. Poverty, Welfare and Social Ties in Modern Europe, Nueva York y Oxford, Berghahn, 2016.

Araya Espinoza, Alejandra, "De los límites de la modernidad a la subversión de la obscenidad: vagos, mendigos y populacho en México, 1821-1871", en FALCón (coord.), 2005, pp. 45-97. 
ArÉCHIGA, Ernesto, “Educación, propaganda o 'dictadura sanitaria’. Estrategia discursiva de higiene y salubridad pública en el México posrevolucionario, 1917-1945", en Estudios de Historia Moderna y Contemporánea, 33 (ene.-jun. 2007), pp. 57-87.

Arrom, Silvia, "Vagos y mendigos en la legislación mexicana, 1745-1845", en Beatriz Bernal (coord.), 1986, pp. 115-157. Disponible en: http://www. bibliojuridica.org/libros/2/721/10.pdf (consulta: 1/03/2016).

Arrom, Silvia Marina, Volunteering for a Cause: Gender, Faith, and Charity in Mexico from the Reform to the Revolution, Albuquerque, The University of New México, 2016.

Arrom, Silvia Marina, Para contener al pueblo: el Hospicio de Pobres de la Ciudad de México (1774-1871), México, Centro de Investigaciones y Estudios Superiores en Antropología Social, 2011.

BASTIAN, Jean-Pierre, Los disidentes: sociedades protestantes y revolución en México, 1872-1911, México, Fondo de Cultura Económica, 2015.

Bernal Beatriz (coord.), Memoria del IV Congreso de Historia del Derecho Mexicano (1986), México, Instituto de Investigaciones Jurídicas-Universidad Nacional Autónoma de México, 1986, t. 1, pp. 115-157. Disponible en http:// www.bibliojuridica.org/libros/2/721/10.pdf (consulta: 1/03/2016).

Beteta, Ramón, La mendicidad en México, México, Beneficencia Pública, A. Mijares y Hno., 1931.

CÁrdenas, Enrique, "La economía mexicana en el dilatado siglo xx, 19292009”, en KunTz Ficker (coord.), 2010, pp. 503-548.

CASTEL, Robert, Las metamorfosis de la cuestión social. Una crónica del salariado, Barcelona, Paidós, 1997.

Censo General de la República Mexicana, 1910. Tabuladores básicos, Departamento de Estadística Nacional, http://www.beta.inegi.org.mx/proyectos/ ccpv/1900/default.html. Consultado el 27 de mayo de 2016.

Cerdá, Juan Manuel, Gloria Guadarrama, María Dolores Lorenzo y Beatriz Moreyra (coords.), El auxilio en las ciudades. Instituciones, actores y modelos de protección social. Argentina y México: siglos XIX y XX, Zinacantepec, Estado de México, El Colegio Mexiquense, 2015. 
Civera Cerecedo, Alicia, La escuela como opción de vida: la formación de maestros normalistas rurales en México, 1921-1945, Zinacantepec, Estado de México, El Colegio Mexiquense, 2008.

Delpar, Helen, Looking South: The Evolution of LA, 1850-1975, Tuscaloosa, Alabama, The University of Alabama Press, 2008.

Dion, Michelle L., Workers and Welfare: Comparative Institutional Change in Twentietn Century Mexico, Pittsburgh, University of Pittsburgh, 2010.

Drinot, Paulo y Alan Knight (coords.), La Gran Depresión en América Latina, México, Fondo de Cultura Económica, 2016.

Durand, Jorge, "Un punto de partida. Los trabajos de Paul S. Taylor sobre la migración mexicana a Estados Unidos”, en Frontera Norte, 12 (23) (ene.-jun. 2000), pp. 51-64.

Ervin, Michael A., "The 1930 Agrarian Census in Mexico: Agronomists, Middle Politics, and the Negotiation of Data Collection", en The Hispanic American Historical Review, 87: 3 (2007), pp. 537-570.

Evangelista, Elí, Historia del trabajo social en México, México, Plaza y Valdés, Universidad Nacional Autónoma de México, 1998.

FALcón, Romana (coord.), Culturas de pobreza y resistencia: estudios de marginados, proscritos y descontentos, México, El Colegio de México, Universidad Autónoma de Querétaro, 2005.

García Dauder, Silvia, "La historia olvidada de las mujeres de la Escuela de Chicago", en Revista Española de Investigaciones Sociológicas, 131 (2010), pp. 11-41.

García de los Arcos, María Fernanda (coord.), La fuente hemerográfica en la diacronia: variedad de enfoques, México, Universidad Autónoma Metropolitana-Azcapotzalco, 2015.

Guadarrama, Gloria, Entre la caridad y el derecho. Un estudio sobre el agotamiento del modelo nacional de asistencia social, México, El Colegio Mexiquense, Comité Editorial de la Administración Pública Estatal, 2001.

Hernández, Alicia (dir.) y Ariel Rodríguez Kuri (coord.), México contemporáneo, 1808-2014. La población y la sociedad, México, El Colegio de México, Fundación Mapfre, Fondo de Cultura Económica, 2015. 
Howard, Ella, Homeless. Poverty and Place in Urban America, Nueva York, University of Pennsylvania, 2013.

Kiddle, Amelia y María L.O. MuÑoz, Populism in Twentieth Century Mexico: The Presidencies of Lázaro Cárdenas, Arizona, University of Arizona, 2010.

Knight, Alan, "Carácter y repercusiones de la Gran Depresión en México", en DRINot y Knight (coords.), 2016, pp. 269-307.

Kuntz Ficker, Sandra (coord.), Historia económica general de México. De la Colonia a nuestros días, México, El Colegio de México, Secretaría de Economía, 2010.

Lida, Clara E. y Sonia Pérez Toledo (comps.), Trabajo, ocio y coacción. Trabajadores urbanos en México y Guatemala en el siglo XIX, México, Universidad Autónoma Metropolitana, 2001.

Lira, Carlos y Ariel Rodríguez Kuri (eds.), Ciudades mexicanas del siglo XIX. Siete estudios históricos, México, El Colegio de México, 2009.

Lorenzo Río, María Dolores, "Los mendigos en la ciudad de México. Perfiles de la pobreza urbana a finales del siglo XIX", en Cerdé, Guadarrama, LORENZO y MOREYRA (coords.), 2015, pp. 341-365.

Lorenzo Río, María Dolores, "Los indigentes ante la asistencia pública. Una estrategia para sobrevivir en la ciudad de México, 1877-1905", en Historia Mexicana, LXII: 1 (245) (jul.-sep. 2012), pp. 195-247.

Lorenzo Río, María Dolores (comp.), Obras para el estudio de la asistencia en México. Siglo XIX, Zinacantepec, Estado de México, El Colegio Mexiquense, 2016.

LLinás Álvarez, Edgar, Vida y obra de Ramón Beteta, México, Galve, 1996.

May, Christina, "Poverty in Transnational Discourses: Social Reformers. Debates in Germany and the Netherlands around 1900", en Althammer, Gestrich y GründLER (eds.), 2014, pp. 21-41.

Montalvo Ortega, Enrique (coord.), Historia de la cuestión agraria mexicana. Modernización, luch a agraria y poder político, 1920-1934, México, Siglo Veintiuno editores, 1988.

Оснон, Enrique, "Coercion, Reform, and the Welfare State”, en The Americas, 58 (2001), pp. 39-64. 
O'Connor, Alice, Poverty Knowledge. Social Science, Social Policy, and the Poor in Twentieth-Century V.S. History, Nueva Jersey, Princeton University Press, 2001.

Palacios, Guillermo, "The Social Science, Revolutionary Nationalism and Interacademic Relations. Mexico and the United States, 1930-1940”, en KidDle y MuÑoz, 2010, pp. 58-70.

Pérez Montfort, Ricardo, Tolerancia y probibición. Aproximaciones a la historia social y cultural de las drogas en México, 1840-1940, México, Debate, 2016.

Pérez Toledo, Sonia, "Los vagos de la ciudad de México y el Tribunal de Vagos en la primera mitad del siglo XIX”, en Secuencia. Revista de Historia y Ciencias Sociales, 27 (sep.-dic. 1993), pp. 27-44.

Piccato, Pablo, Ciudad de sospechosos: crimen en la Ciudad de México, 19001931, México, Centro de Investigación y Estudios Superiores de Antropología Social, 2010.

Quinto Censo de Población, 1930. Poblaciones de las capitales de entidad. Tabulados básicos, Departamento de Estadística Nacional en http://www3. inegi.org.mx/sistemas/tabuladosbasicos/default.aspx?c=16767\&s=est. Consultado el 17 de mayo de 2016.

Riguzzi, Paolo y Patricia de los Ríos, Las relaciones México-Estados Unidos, 1752-2010, t. II. ¿ Destino no manifiesto? 1867-2010, México, Universidad Nacional Autónoma de México, Centro de Investigación sobre América del Norte, Secretaría de Relaciones Exteriores, 2012.

Riguzzi, Paolo (comp.), Las exposiciones de motivos de los presupuestos federales, 1869-1930. Recopilación documental y estudio, Zinacantepec, Estado de México, El Colegio Mexiquense, Asociación Mexicana de Historia Económica, 2016.

Ríos, Andrés, "La psicosis del repatriado. De los campos agrícolas en Estados Unidos al Manicomio La Castañeda en la ciudad de México, 1920-1944”, en Mexican Studies/Estudios Mexicanos, 27: 2 (verano 2011), pp. 361-384.

Rivera Mir, Sebastián, "La experiencia de los centroamericanos becados en México (1922-1928). Entre carencias, vida académica y propaganda revolucionaria", en Latinoamérica [en línea], 55 (dic. 2012) [consultado 17 de octubre de 2016], pp. 185-214, disponible en: http://www.scielo.org.mx/pdf/latinoam/ n55/n55a8.pdf. 
Sanders, Nichole, Gender and Welfare in Mexico. The Consolidation of a Posrevolutionary State University Park, Pa., Pennsylvania State University Press, 2011.

SAnguino, Laurencio y Mauricio Tenorio, "Orígenes de una ciudad mexicana. Chicago y la ciencia del Mexican Problem”, en Lira y Rodríguez (eds.), 2009, pp. 257-314.

Simpson, Eyler N., The Ejido. Mexicos's Way Out, Chapel Hill, University of North Carolina, 1937.

Speckman Guerra, Elisa, "Los jueces, el honor y la muerte. Un análisis de la justicia (ciudad de México, 1871-1931)”, en Historia Mexicana, Lv: 4 (220) (abr.-jun. 2006), pp. 1411-1466.

Steelman, Albert Judson, "Charities for Children in the City of Mexico", tesis de licenciatura en filosofía, Illinois, University of Chicago, 1907.

Tenorio Trillo, Mauricio, "Stereophonic Scientific Modernisms: Social Science between Mexico and the United States, 1880s-1930s", en The Journal of American History (dic. 1999), pp. 1156-1187.

Urías Horcasitas, Beatriz, "Eugenesia e ideas sobre las razas en México, 1930-1950”, en Historia y Grafía, 17 (2001), pp. 171-205.

URías Horcasitas, Beatriz, "Eugenesia y aborto en México (1920-1940)”, en Debate Feminista, 27 (abr. 2003), pp. 305-322.

Urías Horcasitas, Beatriz, "Locura y criminalidad: degeneracionismo e higiene mental en el México posrevolucionario, 1920-1940”, en AgOstoni y SPECKMAN Guerra (eds.), 2005, pp. 347-383.

Vivaldo Martínez, Juan Pablo, "Viejos y ancianos. La vejez vista a través de la prensa porfiriana", en GARCÍA DE LOS ARCOS (coord.), 2015, pp. 109-123.

Wallerstein, Immanuel, El moderno sistema mundial. El triunfo del liberalismo centrista, 1789-1914, México, Siglo Veintiuno editores, 2014.

Wheat, Kathryn Ann, "Personal encounters: Mexico and the United States in the 1920 s through the letters of Dr. Eyler Newton Simpson and the National University of Mexico's summer school for foreigners", tesis de maestría, Austin, Texas, Universidad de Texas, 2002.

Zapata, Francisco, El sindicalismo latinoamericano, México, El Colegio de México, 2013. 